\title{
Reputational Comparative Advantage and Multinational Enterprise
}

\author{
Richard Chisik*
}

April 2001

\begin{abstract}
$\underline{\text { Abstract }}$
For a firm without a readily identifiable brand name, quality reputation may solely reflect the country of origin. In this paper we endogenize country-of-origin reputations and show that these selffulfilling reputations determine not only the average quality of a country's exports but also the type of products in which a country specializes. Hence, the pattern of international trade can be determined by reputational comparative advantage. Specialization according to reputational comparative advantage can also establish the location of the host and the parent firm in a multinational enterprise. Furthermore, multinationals that internalize production in a single firm can eradicate a low reputation equilibrium and, therefore, can increase host-country welfare by a greater amount than under a licensing arrangement. Finally, this reputation effect can identify whether internalization, or licensing, is more likely to occur.
\end{abstract}

JEL Classification: F12, F23, J71, L15

Key Words: Country-of-Origin, Quality Reputations, Multinational Enterprise, Internalization, Statistical Discrimination.

* Department of Economics DM-309C, Florida International University, Miami, FL, 33199; E-mail: chisikr@fiu.edu. Phone: (305) 348-3286; Fax: (305) 348-1524.

For helpful comments and discussion I am grateful to Kyle Bagwell, Kiminori Matsuyama, Robert Porter, Steve Ross and participants at the Conference on Analytical Economic Geography and Regional Change, the Mid-West International Economic Meetings and the Western Economic Association Meetings. I am solely responsible for any remaining errors. 


\section{Introduction}

When cultivating a new export market or attempting to expand its share of an existing market, an exporter is likely to find that it has been preceded by its reputation. Absent a readily identifiable brand name, quality reputation may solely reflect the country of origin. For example, when consumers are presented with a large amount of complex product information they may use the country of origin as a heuristic in forming product impressions without considering other product attributes. ${ }^{1}$ In this paper we show that this heuristic decision making process can affect a firm's quality decision and can, therefore, become self-fulfilling. Hence, any bias that consumers have may be well-founded, however, it is only correct because firms respond rationally to it.

An interesting example of a self-fulfilling unfavorable quality reputation in international trade is given by Colombia's garment industry (Morawetz, 1981.) A single Colombian garment firm took a contract (for 50,000 men's suits) that was beyond their capability. The poor-quality result so tarnished the American importer's name that other high-quality importers become wary of Colombian-sewn garments. With the payoff to high-quality production reduced, Colombian garment firms then concentrated on low-quality markets, and the newly found unfavorable reputation was justified.

In the model we construct here consumers see only a noisy signal of the product's quality at the time of purchase, therefore, their posterior beliefs are based on this noisy signal and the country-of-origin reputations. As will be made clear below, higher-quality firms benefit more from an increase in their country's reputation so that a better reputation generates an increase in the percentage of high-quality firms. It is in this way that the reputation becomes self-fulfilling and ex-ante identical countries can be correctly perceived as differing in their percentage of high-quality producers.

\footnotetext{
${ }^{1}$ See Bodenhauser and Lichtenstein (1987) and Bodenhauser and Wyer (1985). Additionally, Han and Terpstra (1988) show that products with a country-of-origin label from a developing country are rated inferior to those with an industrial country-of-origin label. Head (1993) reports that a "Made in Germany" label evokes the concepts of reliability, precision and punctuality. Bilkey and Nes (1982) find that these biases persist even when test subjects receive only country-of-origin label and no other product information.
} 
We next introduce an economy with two sectors. One sector produces more complex goods where high quality is not easily verified and is more essential to the product's performance. These may be technology-intensive products, or they may consist of the design and marketing of the goods produced in the other sector. In particular, high-quality production costs and the consumer's value for high quality goods is greater in this sector. We show that this sector becomes more profitable as the country-of-origin reputation increases. Hence, if one country's equilibrium reputation is low and the other country's equilibrium reputation is high, then the pattern of specialization and international trade can be determined solely by "reputational comparative advantage". ${ }^{2}$ Finally, we show that reputational comparative advantage can overshadow a small technological comparative disadvantage in determining the pattern of international trade.

Given this pattern of trade and specialization, based on reputational comparative advantage, a highreputation firm may expend resources to establish a MNE in the low-reputation country. For example, many MNE products require the differing specializations of both the high and low reputation countries. Although differing in motivation, this result accords well with more traditional models of vertical MNE. ${ }^{3}$ However, this impetus for MNE (as well as its more traditional counterparts) does not explain why the MNE would choose FDI over a less costly licensing arrangement. ${ }^{4}$ The quality uncertainty in our model along with the difference in equilibrium reputations allows us to address this question.

In particular, appropriable reputational rents are generated by FDI when the high-reputation parent firm procures, and internalizes production with, a low-reputation host firm. This FDI "breaks" the low-

\footnotetext{
${ }^{2}$ An example of the effect of reputation on a country's chosen specialization is given by Wortzel and Wortzel (1979) who show that Colombia's fluctuating reputation was an important determinant of their chosen production sector within the garment industry. They show, first, that the, less-complex, assembly stage in the garment industry is less profitable than the reputation-dependent, more-complex, design and marketing stage. They then provide evidence that Colombian firms, with a low-quality reputation in the U.S., import these services from abroad. For markets where they do not have a low-quality reputation, such as the Caribbean, they produce their own design and marketing services.

${ }^{3}$ See for example the literature cited in Helpman and Krugman (1985) and Markusen (1995) as well as papers by Hanson (1996) and Rodríguez-Clare (1996).

${ }^{4}$ We use the term FDI to signify production internalized in a single firm so that the host firm is an ownedsubsidiary of the parent firm. We contrast this with the case where the parent firm licenses its technology or brand name to its host country affiliate. We use the term licensing to also refer to joint ventures between the parent and the host country affiliate. There are subtle differences between these two MNE forms, however, they are similar in that they both are less costly and require less parent firm involvement than does FDI.
} 
reputation equilibrium of the host firm and generates reputational rents. No reputational rents are generated by licensing. We find that products from the more sophisticated and more reputation intensive sector generate greater reputational rents, so that FDI is more prevalent than licensing for these more sophisticated products. ${ }^{5}$ Additionally, a higher reputation in the parent country generates more outbound FDI and (all things equal) a lower reputation in the host country generates more inbound FDI. When countries differ in their ex-ante production capabilities (so that all else is not equal) the set of correct-in-equilibrium reputations differ as well. For a country with very low production capabilities, production of the more sophisticated products is less profitable in any equilibrium. Countries with low production capabilities, therefore, attract relatively more FDI in less sophisticated products and they are more likely to not attract any FDI at all. Finally, FDI may have external effects on the host country's quality reputation. As long as the external effects are not too negative (they may very well be positive), the ability of FDI to generate production under a more favorable equilibrium makes it more beneficial than licensing for the host country.

Armington (1969) is the first, to our knowledge, to formally recognize that consumers may distinguish seemingly identical products by their country of origin. He did not endogenize these country-oforigin reputations nor did he recognize that they may serve as a source of comparative advantage. Vernon (1966) notes that industrialized countries (with an established quality reputation) produce and export new products of unverifiable quality and developing countries produce standardized products whose quality is easily verified. Although our explanation differs, our results correspond well with his observations.

Bagwell and Staiger (1989), Bagwell (1991), Mayer (1984), Grossman and Horn (1988), and Chen (1991) examine informational barriers to entry in international trade. The latter three also introduce importers with exogenous, and pessimistic, beliefs about export quality. Because these authors recognize

\footnotetext{
${ }^{5}$ Markusen (1995) and Caves (1996) survey a broad empirical literature that lends strong support to this theoretical finding on the types of products in which FDI is more likely than licensing.
} 
that exogenous beliefs are not consistent with a common prior in equilibrium, they do not fully develop the implications of pessimistic beliefs. ${ }^{6}$

Ethier (1986), Horstman and Markusen (1995) and Ethier and Markusen (1996) formalize rationales for vertical integration and extend them to an international context in order to address theoretically the question of internalization in the MNE. In Horstman and Markusen (1987) quality uncertainty leads to internalization over licensing. We extend this literature by proposing a new rationale for internalization and by determining when internalization is more likely to occur. Markusen (1989), Hanson (1996) and Rodríguez-Clare (1996) also analyze FDI's effect on welfare in the host country. Whereas these authors are concerned with the advantages and disadvantages of intermediate inputs that are imported from the parent country, our focus is on quality reputation.

Our approach to reputation and equilibrium selection based on conventions is related to Arrow's (1974) model of statistical discrimination in labor markets. An alternative approach to reputation formation is provided by Tirole (1996) who provides a structural analysis of how bad reputations can persist (and worsen) for a group over time. Although not concerned with the same issues as the present paper, his model could be easily adapted to these issues, however, this alternative approach would not change our results.

The paper is divided into five sections. In the next section we develop a model of self-fulfilling country-of-origin reputations. In the third section we introduce reputational comparative advantage. In the fourth section we introduce MNE. The fifth section contains our conclusions.

\section{Self-Fulfilling Country-of-Origin Reputations}

\footnotetext{
${ }^{6}$ Chiang and Masson (1988) examine the relationship between country characteristics and the moral hazard in quality selection. In their paper, firms view quality as a strategic substitute that yields an unique equilibrium with inefficiently low quality provision. As a result, the inefficiency increases with the number of exporting firms. Although interesting, their model produces the rather perverse prediction that larger countries (such as Germany, Japan and the United States) should have lower quality than smaller countries (such as Colombia, Korea and Taiwan). Haucap et al (1997) provide a different explanation for the relationship between country characteristics and country-of-origin quality reputation. They show that when firms are liquidity constrained, so that burning money is not a viable option, ongoing production in a high-cost country can signal high product quality.
} 


\section{A. A Noisy Signaling Model of an Endogenous Quality Choice.}

In the simple model we present here there are two types of countries: "A" and "B". The countries are identical in every respect except for their "A" or "B" label. ${ }^{7}$ Although we are interested in understanding the pattern of resource allocation and trade between an "A" and a "B" country, to help develop intuition, and to focus on the relationship between country-of-origin reputation and quality choice, we start by analyzing the interaction of a single exporting firm and the foreign importers of its good. We extend this analysis to general equilibrium in the following sections.

A firm produces its entire capacity, which is normalized to one, for export. The firm chooses the unobservable quality (at the time of purchase) of the good: $\mathrm{Q} \in\{\mathrm{L}, \mathrm{H}\}$. The additional cost of high quality production is firm specific and is given by the firm's type: $\theta \in \Theta=[\underline{\theta}, \bar{\theta}]$. The firm has private information about its type, which is drawn from a smooth and commonly known distribution function $\mathrm{F}(\theta)$. The firm also has an unalterable label, $\mathrm{i} \in\{\mathrm{A}, \mathrm{B}\}$, indicating country of origin. It is common knowledge that the label contains no direct information, in the sense that the distribution of types is independent of i: $F(\theta \mid i)=F(\theta)$ for all $i$. The label may, however, provide information about the firm's unobservable quality choice. The firm also chooses a sector of the economy $S \in\{\alpha, \beta\}$.

The importers (at least two) bid for the firm's good and the firm sells to the highest bidder. ${ }^{89}$ In the case of a tie, the firm divides the good equally among all importers offering the highest price. The

\footnotetext{
${ }^{7}$ Although it is reasonable to expect that countries differ in technology, efficiency and production costs, it remains of interest to show that reputation can matter even when countries are identical. The point we develop here is that for any level of technological sophistication there is more than one "correct" belief. Hence, the difference in reputations may be much wider, or much narrower, than what the technology differences lead one to expect.

${ }^{8}$ If instead of importers bidding for the firm's output, the firm were to set the price, then any announced price by the firm may signal their chosen quality. In particular, if firms that choose high quality choose a different price than firms that choose low quality, then country-of-origin conjectures are irrelevant in the resulting separating equilibrium. By assuming that the importers bid for the firm's product we are ensuring that price cannot signal the firm's unobservable quality. We do not make this assumption to detract from the importance of price signaling (although it may not always be an option for a small exporter in a small country), but rather to limit our analysis to a one dimensional signal. Alternatively, the arguments in this paper can be worked out for the case of a noisy price signal of product quality. An example is provided in Appendix B of a working paper available upon request.

${ }^{9}$ By assuming that there are at least 2 importers who bid for the firm's product we are effectively assuming that the firm has monopoly power. Giving the firm monopoly power yields a straightforward division of the gains from
} 
importers observe the sector and the country of origin label, but do not observe the firm's type or its unobservable quality choice. Instead, the importers only observe a noisy signal about Q, which is denoted as $\mathrm{Z}=\mathrm{Q}+\varepsilon$, where $\varepsilon$ is distributed according to the smooth function $\mathrm{G}(\varepsilon)$. Hence, an importer's bid is a function $\mathrm{P}(\mathrm{S}, \mathrm{Z}, \mathrm{i})$. Given its type and label a firm chooses $\{\mathrm{S}, \mathrm{Q}\}$ to maximize its expected profits, which is the difference between its conditionally expected revenue and its cost:

$$
\mathrm{E} \Pi(\theta, \mathrm{i})=\mathrm{E} \Pi(\theta, \mathrm{S}(\theta, \mathrm{i}), \mathrm{Q}(\theta, \mathrm{i}), \mathrm{i})=\mathrm{E}_{Z \mid \mathrm{Q}}[\max \mathrm{P}(\mathrm{S}, \mathrm{Z}, \mathrm{i})]-\mathrm{C}(\theta, \mathrm{S}, \mathrm{Q}) .
$$

The timing of the game is as shown in figure 1 below.

\section{FIGURE 1 GOES APPROXIMATELY HERE.}

We ignore the sector decision for the remainder of this section and analyze the firm's quality decision conditional on their chosen sector. In the next section we work backwards to find the firm's chosen sector. To unclutter notation we temporarily remove this fixed sector choice from the analysis and consider the firm's restricted expected profit function:

$$
\mathrm{E} \Pi(\theta, \mathrm{i})=\mathrm{E} \Pi(\theta, \mathrm{Q}(\theta, \mathrm{i}), \mathrm{i})=\mathrm{E}_{\mathrm{Z|Q}}[\max \mathrm{P}(\mathrm{Z}, \mathrm{i})]-\mathrm{C}(\theta, \mathrm{Q})
$$

Consider first the cost function: $\mathrm{C}(\theta, \mathrm{Q})$. The unobservable $\theta$ indexes the additional cost of producing high quality, an activity that is more costly for higher types: $\mathrm{C}_{\theta}(\cdot, \mathrm{H})>0 .{ }^{10}$

$$
\mathrm{C}(\theta, \mathrm{H})>\mathrm{C}(\theta, \mathrm{L})=0 \text { for all } \theta, \mathrm{C}_{\theta}(\cdot, \mathrm{H})>0
$$

We now analyze the firm's conditionally expected revenue function $E_{Z \mid Q}[\max P(Z, i)]$. Although importers do not observe the firm's chosen quality before purchase, they do observe some noisy information as captured by the noisy signal $\mathrm{Z}=\mathrm{Q}+\varepsilon$. It is reasonable to expect that this information is

trade. Other specifications are, of course, possible, however, as long as they allow the firm to retain some of the surplus they create by producing high quality, these alternative specifications do not change our results. Alternatively, in a competitive market the firm would retain none of the surplus created by their high-quality production and would have no incentive to produce high quality.

${ }^{10} \mathrm{We}$ follow the convention that a subscript refers to the partial derivative of the function with respect to the subscript: $\partial \mathrm{C}(\cdot, \mathrm{H}) / \partial \theta \equiv \mathrm{C}_{\theta}(\cdot, \mathrm{H})$. 
meaningful, in that a higher quality product is correlated with a higher noisy signal of product quality. ${ }^{11}$

Hence, we assume that the conditional density of $Z$ given $Q, g(Z \mid Q)$, satisfies the strict monotone-

likelihood ratio property (MLRP).

$$
Z^{\prime}>\mathrm{Z} \Rightarrow \mathrm{LR}\left(\mathrm{Z}^{\prime}\right)=\mathrm{g}\left(\mathrm{Z}^{\prime} \mid \mathrm{L}\right) / \mathrm{g}\left(\mathrm{Z}^{\prime} \mid \mathrm{H}\right)<\mathrm{g}(\mathrm{Z} \mid \mathrm{L}) / \mathrm{g}(\mathrm{Z} \mid \mathrm{H})=\mathrm{LR}(\mathrm{Z})
$$

MLRP implies first order stochastic dominance (FOSD); therefore, the cumulative distribution function of $\mathrm{Z}$ given $\mathrm{Q}, \mathrm{G}(\mathrm{Z} \mid \mathrm{Q})$, satisfies FOSD. We assume, as well, that $\mathrm{g}(\mathrm{Z} \mid \mathrm{Q})$ has a non-moving support so that no received signal can be ruled out for a particular product quality.

Next consider the importer's objective. Each importer has the same von Neumann-Morgenstern subutility function, $v(Q)$ which is inelastic for the firm's entire capacity. The importer naturally values higher quality so that $v(H)>v(L) \geq 0$. The importer's belief on the probability that a firm chose high quality, conditional on the importer's observation of the noisy signal and the country of origin can be written as $\mathrm{b}(\mathrm{Z}, \mathrm{i})=\operatorname{Pr}(\mathrm{H} \mid \mathrm{Z}, \mathrm{i})$. The importer chooses a price $\mathrm{P}$ to maximize their indirect utility function $\mathrm{U}=\gamma(\mathrm{P}) \cdot[\mathrm{u}(\mathrm{Z}, \mathrm{i})-\mathrm{P}]+\mathrm{Y}$, where $\mathrm{u}(\mathrm{Z}, \mathrm{i})$ is their expected utility form purchase, $\mathrm{Y}$ is an adequately large, exogenous, source of income, and $\gamma(\mathrm{P})$ indicates their consumption level of the good which depends on their chosen price $\mathrm{P}$ and the bid of all the other importers.

$\mathrm{v}(\mathrm{H})>\mathrm{v}(\mathrm{L}) \geq 0 ; \mathrm{u}(\mathrm{Z}, \mathrm{i})=\mathrm{b}(\mathrm{Z}, \mathrm{i}) \cdot \mathrm{v}(\mathrm{H})+(1-\mathrm{b}(\mathrm{Z}, \mathrm{i})) \cdot \mathrm{v}(\mathrm{L}) ; \mathrm{U}=\gamma(\mathrm{P}) \cdot[\mathrm{u}(\mathrm{Z}, \mathrm{i})-\mathrm{P}]+\mathrm{Y} \quad$ (A3-Utility)

\section{B. Description of the Equilibrium}

A (sequential) equilibrium is a collection of strategies and beliefs $\{Q(\theta, i), P(Z, i), b(Z, i)\}$ which satisfy the following three conditions. First, sequential rationality of the firm's strategy and of each importer's strategy requires that:

\footnotetext{
${ }^{11}$ The importer may see observable quality (e.g. fit, finish, etc.) or a sample shipment. A better sample shipment or better observable quality should be correlated with higher unobservable quality, however, stochastic elements outside of a firms control (such as international shipping) ensures that this correlation is not perfect. Similarly, a guarantee may provide information about the unobservable product quality. High-quality firms should on average find it easier to offer a better warranty, however, this correlation is not perfect. In particular, we consider the "fine print" that is written in to any guarantee, or the natural uncertainty about a firm's willingness to uphold their guarantee, as signal noise. Presumably, these information imperfections and legal uncertainties grow in an
} 


$$
\begin{aligned}
& \mathrm{Q}(\theta, \mathrm{i}) \in \operatorname{argmax}_{\mathrm{Q}}\left\{\mathrm{E}_{\mathrm{Z} \mid \mathrm{Q}}[\mathrm{P}(\mathrm{Z}, \mathrm{i})]-\mathrm{C}(\theta, \mathrm{Q})\right\} \\
& \mathrm{P}(\mathrm{Z}, \mathrm{i}) \in \operatorname{argmax}_{\mathrm{P}} \gamma(\mathrm{P}) \cdot[\mathrm{u}(\mathrm{Z}, \mathrm{i})-\mathrm{P}]+\mathrm{Y}
\end{aligned}
$$

Second, because the signal is noisy, with a non-moving support, all actions are on the equilibrium path, therefore, for all Z, equilibrium beliefs are derived by Bayes' rule:

$$
\mathrm{b}(\mathrm{Z}, \mathrm{i})=\operatorname{Pr}(\mathrm{H} \mid \mathrm{Z}, \mathrm{i})=\frac{1}{1+\operatorname{LR}(\mathrm{Z}) \frac{1-\rho_{\mathrm{i}}}{\rho_{\mathrm{i}}}}
$$

The importer's conjecture that a firm in country $i$ will choose high quality is $\rho_{i}=\operatorname{Pr}(H \mid i)$ (the country-oforigin reputation.) Although $\rho_{\mathrm{i}}$ is presently taken as a parameter the third equilibrium condition states that it must be correct in equilibrium and, therefore, it must be endogenized. The third equilibrium condition can be more intuitively expressed after the statement of the following lemma.

Lemma 1: Assume $(A 1, A 3)$ are satisfied. Then $\mathrm{P}(\mathrm{Z}, \mathrm{i})=\mathrm{u}(\mathrm{Z}, \mathrm{i})$, for all importers are the unique equilibrium prices.

All proofs are contained in appendix A of a working paper, available upon request.

Lemma 1 indicates that Bertrand competition among the importers results in each bidding a price equal to their expected value for the good. It suggests that our model can be interpreted as describing a firm in a small country (that cannot affect world price) and that, therefore, can sell its entire output at the going world price - for a good of that perceived quality. ${ }^{12}$

Using Lemma 1, the firm's conditionally expected revenue can be written as

$$
\bar{P}(Q, i)=E_{Z \mid Q}[\max P(Z, i)]=\int_{Z} u(Z, i) d G(Z \mid Q) .
$$

international setting, so that, at best, a guarantee is an informative, but noisy signal of product quality.

${ }^{12}$ The garment industry provides a useful analogy. Much of the sewing of garments is done in small shops in newly industrializing countries. These shops often contract to sell their entire output to one or two importers for a set period of time (because the patterns and designs are dictated by the importer, the firm is, in a sense, merely renting their capacity and managerial talent). 
Remembering that the low-quality firm's profit is the same for all $\theta$, the marginal firm, $\theta^{\mathrm{H}}$, is defined as the solution to:

$$
\mathrm{E} \Pi\left[\theta^{\mathrm{H}}, \mathrm{H}, \rho_{\mathrm{i}}\right]-\mathrm{E} \Pi\left[\theta, \mathrm{L}, \rho_{\mathrm{i}}\right]=0 .
$$

Hence, $\theta^{\mathrm{H}}$ is the type of the firm that is indifferent between high and low quality and is, therefore, the highest type choosing high quality. All higher types choose low quality and all lower types choose high quality. Thus, $\mathrm{F}\left(\theta^{\mathrm{H}}\right)$ is the empirical measure of firms choosing high quality. The third equilibrium condition, consistency with a common prior distribution, then requires:

$$
\begin{aligned}
& \rho_{\mathrm{i}}=\operatorname{Pr}(\mathrm{Q}=\mathrm{H} \mid \mathrm{i})=\operatorname{Pr}\left(\mathrm{E} \Pi\left[\theta, \mathrm{H}, \rho_{\mathrm{i}}\right] \geq \mathrm{E} \Pi\left[\theta, \mathrm{L}, \rho_{\mathrm{i}}\right]\right)=\operatorname{Pr}\left(\mathrm{E} \Pi\left[\theta, \mathrm{H}, \rho_{\mathrm{i}}\right] \geq \mathrm{E} \Pi\left[\theta^{\mathrm{H}}, \mathrm{H}, \rho_{\mathrm{i}}\right]\right)= \\
& \operatorname{Pr}\left[\mathrm{C}(\theta, \mathrm{H}) \leq \mathrm{C}\left(\theta^{\mathrm{H}}\left(\rho_{\mathrm{i}}\right), \mathrm{H}\right)\right]=\operatorname{Pr}\left(\theta \leq \theta^{\mathrm{H}}\left(\rho_{\mathrm{i}}\right)\right)=\mathrm{F}\left(\theta^{\mathrm{H}}\left(\rho_{\mathrm{i}}\right)\right), \quad \text { (E3-Consistency) }
\end{aligned}
$$

so that the importer's conjecture induces that same measure of firms to choose high quality.

\section{Self-fulfilling Conjectures}

To see how multiple equilibria may arise we first establish the effect of country-of-origin conjectures, $\rho_{\mathrm{i}}$, on quality choice, $\mathrm{Q}$, and on the marginal firm, $\theta^{\mathrm{H}}$.

Proposition 1: If A1-A3 are satisfied, then for $\rho_{\mathrm{i}}$ near zero, $\theta^{\mathrm{H}}$ is strictly increasing in $\rho_{\mathrm{i}}$ and, as $\rho_{\mathrm{i}}$ approaches one, $\theta^{\mathrm{H}}$ is strictly decreasing in $\rho_{\mathrm{i}}$.

The intuition behind Proposition 1 is as follows. If importers have the most pessimistic conjectures $\left(\rho_{i}=0\right)$ then any realized signal $(Z)$, no matter how high, is attributed to a low quality firm and has no effect on the importer's belief. Hence, no firm would choose high quality in this case. An increase in $\rho_{i}$, from this most pessimistic level, indicates that higher signals have a positive effect on the importer's belief and, therefore, raise the exporter's incentive in choosing high quality (so that a higher signal is more likely

observed by the importer.) As more firms choose high quality, the measure of high-quality firms and $\theta^{\mathrm{H}}\left(\rho_{\mathrm{i}}\right)$ are increasing in $\rho_{\mathrm{i}}$. It is in this way that the conjecture influences the firm's quality calculus and becomes self-fulfilling. For a very high conjecture ( $\rho_{\mathrm{i}}$ near 1 ) importers believe that the firm is of high quality, 
irrespective of the observed signal realization. The firm is, therefore, less concerned with a high signal. This reduced desire for a high signal lessens the firm's desire to become high quality. It is, therefore, seen that very high conjectures induce a reduction in the measure of high quality firms so that $\theta^{\mathrm{H}}\left(\rho_{\mathrm{i}}\right)$ is decreasing in $\rho_{\mathrm{i}}$ in this range. Hence, these overly optimistic conjectures cannot be correct in equilibrium.

\section{FIGURE 2 GOES APPROXIMATELY HERE}

The relationship between $\rho_{\mathrm{i}}$ and $\theta^{\mathrm{H}}\left(\rho_{\mathrm{i}}\right)$ suggested by Proposition 1 is illustrated in Figure 2 . Proposition 1, however, only ensures that $\theta^{\mathrm{H}}\left(\rho_{\mathrm{i}}\right)$ is at first increasing and then eventually decreasing in $\rho_{\mathrm{i}}$. It does not ensure that multiple equilibria exist. In particular, if $\mathrm{C}(\theta, \mathrm{H})$ is very high for all exporter types, then no exporter chooses high quality and $\rho_{i}=0$ is the only equilibrium. Similarly, if $C(\theta, H)$ is small and increases slowly, then all firms trivially choose high quality. For multiple equilibria to arise it is, therefore, necessary to place the following restriction on the variation in $\mathrm{C}(\theta, \mathrm{H})$ :

There exists a $\rho^{\prime}=F\left(\theta^{\prime}\right)$ and a $\rho^{\prime \prime}=F\left(\theta^{\prime \prime}\right)$ such that $0<\rho^{\prime}<\rho^{\prime \prime}<1$, and

$$
\mathrm{C}\left(\theta^{\mathrm{H}}\left(\rho_{\mathrm{i}}{ }^{\prime}\right), \mathrm{H}\right)<\mathrm{C}\left(\theta^{\prime}, \mathrm{H}\right)<\mathrm{C}\left(\theta^{\prime \prime}, \mathrm{H}\right)<\mathrm{C}\left(\theta^{\mathrm{H}}\left(\rho_{\mathrm{i}}{ }^{\prime \prime}\right), \mathrm{H}\right) \text {. }
$$

(A4-Variation)

Assumption 4 indicates that there exists a range of values of $\rho_{i}$ and $\theta$ such that expected revenue of a highquality firm is increasing faster in $\rho_{\mathrm{i}}$ than the cost of becoming high-quality is increasing in $\theta$. To see this, note that manipulation of (A4) yields: $\checkmark\left(\mathrm{H}, \rho_{\mathrm{i}}^{\prime \prime}\right)-\checkmark\left(\mathrm{H}, \rho_{\mathrm{i}}^{\prime}\right)>\mathrm{C}\left(\theta^{\prime \prime}, \mathrm{H}\right)-\mathrm{C}\left(\theta^{\prime}, \mathrm{H}\right)$. Put another way, (A4) indicates that multiple reputational equilibria are more likely to exist when firms have similar capabilities, so that the variation in their high-quality cost is small. Similarly, these multiple equilibria are more likely to arise for products in which a high-quality reputation has a larger positive effect on firm revenue.

Proposition 2: Under $(A 1-A 4)$ there generically exists at least three, and an odd number of, equilibria. A more favorable conjecture is associated with a more favorable equilibrium.

Proposition 2 shows that although country of origin may be uncorrelated with any primitive ability to produce high quality, the importers' conjecture correctly correlates them in equilibrium. We now 
consider the welfare properties of the equilibrium set. ${ }^{13}$

Proposition 3: Assume $(A 1-A 4)$. Equilibria where importers have a more favorable conjecture are interim Pareto superior to equilibria that are induced from a less favorable conjecture. A high-quality firm always benefits more than a low-quality firm when the equilibrium conjecture increases.

The intuition behind Proposition 3 is as follows. All firms benefit from a more favorable equilibrium because it increases their expected revenue. Furthermore, because importers pay their expected surplus for the good, they are indifferent over the set of equilibria. The last claim in Proposition 3 is the most interesting. For a higher conjecture to be correct in equilibrium it has to induce some low-quality firms, that were formally at the margin, to become high-quality firms. Hence, high-quality firm profits must increase faster than low-quality firm profits in the move to a more favorable equilibrium.

Finally, using the natural stability condition, $d\left(F\left(\theta^{\mathrm{H}}\left(\rho_{\mathrm{i}}\right)\right)-\rho_{\mathrm{i}}\right) / \mathrm{d} \rho_{\mathrm{i}}<0$ we note that the most unfavorable and all equilibria where $\mathrm{F}\left(\theta^{\mathrm{H}}\left(\rho_{\mathrm{i}}\right)\right)$ crosses the $45^{\circ}$ line from above are stable with respect to a small perturbation of the importers' beliefs, therefore, there are a minimum of 2 stable equilibria.

\section{Reputational Comparative Advantage and the Pattern of International Trade}

We now show that the pattern of trade between two countries may be determined by reputation rather than technological or factor endowment differences. In addition, reputational comparative advantage may, under certain conditions, take precedence over technological comparative advantage.

We extend our model as follows. There are $\mathrm{N}_{\mathrm{i}}$ firms, indexed by $\mathrm{j}$, in country $\mathrm{i}$. The manufactured goods are now produced for consumption by the i identical agents in each country. These "consumers" take the place of the importers in the previous section. The agents' preferences can be represented by the utility function described in A3 and the agents' income is now endogenized as their equal share of the firm's

\footnotetext{
${ }^{13}$ Because each player knows their own type, but the importer doesn't, interim welfare comparisons are the natural choice in this situation. See Holmstrom and Myerson (1983) for further discussion of the appropriate welfare comparison in games of incomplete information.
} 
profits and the wage (normalized to one) that is paid to their one endowed unit of labor. Their identical indirect utility functions can be represented as:

$\mathrm{V}(\mathrm{Z}, \mathrm{P}, \theta, \mathrm{i}, \quad)=\sum_{\mathrm{i}} \sum_{\mathrm{j}} \gamma_{\mathrm{ij}}\left(\mathrm{P}_{\mathrm{ij}}\right) \cdot\left[\mathrm{u}\left(\mathrm{Z}_{\mathrm{j}}, \mathrm{i}\right)-\mathrm{P}\left(\mathrm{Z}_{\mathrm{j}}, \mathrm{i}\right)\right]+\sum_{\mathrm{j}} \mathrm{E \Pi}\left(\theta_{\mathrm{j}}, \mathrm{i}\right) /{ }_{\mathrm{i}}+1=\sum_{\mathrm{j}} \mathrm{E \Pi}\left(\theta_{\mathrm{j}}, \mathrm{i}\right) / \quad{ }_{\mathrm{i}}+1$.

From Lemma 1 all consumers bid $u\left(Z_{j}, i\right)=P\left(Z_{j}, i\right)$. If one consumer bids less than $u\left(Z_{j}, i\right)$, then for that consumer $\gamma_{\mathrm{ij}}=0$. This observation yields the second equality in equation (3). ${ }^{14}$

We now explicitly consider two countries $i \in\{A, B\}$ and two manufacturing sectors, $S \in\{\alpha, \beta\}$.

Firms can produce in either sector and choose their sector after seeing their type and country-of-origin label, but before any other production decisions are made. Within a sector, each firm produces a differentiated version of that sector's good. The sectors differ in their production cost, and consumer value, for high quality products. To be concrete, we assume that the $\alpha$ sector constitutes more sophisticated products than the $\beta$ sector. A related interpretation of the difference between sectors is that the $\beta$ sector comprises assembly of simple electronic items or ready-to-wear apparel and the $\alpha$ sector, on the other hand, consists of the design and marketing of these $\beta$ sector goods.

In particular, we choose a unit of output so that low-quality utility for each sector is the same. Our assumption then implies that high-quality utility is greater in sector $\alpha$. Similarly, low-quality costs are the same in both sectors, however, high-quality production is more expensive in sector $\alpha$.

$$
\begin{aligned}
& \mathrm{v}(\alpha, \mathrm{H})>\mathrm{v}(\beta, \mathrm{H})>\mathrm{v}(\alpha, \mathrm{L})=\mathrm{v}(\beta, \mathrm{L}) \\
& \mathrm{C}(\theta, \alpha, \mathrm{H})>\mathrm{C}(\theta, \beta, \mathrm{H})>\mathrm{C}(\theta, \alpha, \mathrm{L})=\mathrm{C}(\theta, \beta, \mathrm{L})=0 .
\end{aligned}
$$

In the appendix we show that as $\rho_{\mathrm{i}}$ increases, $\alpha$ sector goods become more profitable than $\beta$ sector goods. Hence, sector $\alpha$ products are more reputation intensive. The economic intuition behind this result is

\footnotetext{
${ }^{14}$ We show in Appendix $\mathrm{C}$ of a working paper that by introducing a numeraire good, interpreting each $\theta_{\mathrm{ij}}$ as a specific factor, and allowing labor mobility between the $\mathrm{N}_{\mathrm{i}}$ firms and the numeraire sector, equilibrium for country "i" is then described by equations (E1 - E3), (3) and a resource constraint.
} 
that a larger $\rho_{\mathrm{i}}$ attaches greater posterior probability to high quality, which is more valuable for sector $\alpha$. Hence, there is a single-crossing-property between sectors and conjectures: $\partial \mathrm{E} \Pi(\theta, \alpha, \mathrm{Q}, \cdot) / \partial \rho>$ $\partial \mathrm{E} \Pi(\theta, \beta, \mathrm{Q}, \cdot) / \partial \rho$. Furthermore, there exists a $\rho^{*}$ such that if $\rho_{\mathrm{i}} \leq \rho^{*}$, then high-quality $\beta$ sector goods are more profitable (because of the greater high-quality cost in sector $\alpha$ ); and if $\rho_{\mathrm{i}}>\rho^{*}$, then high-quality $\alpha$ sector goods are more profitable.

Now, an equilibrium where $\rho_{A}=\rho_{B}$ is possible and in this equilibrium there is no impetus for international trade. A more interesting trading equilibrium, where $\rho_{A}>\rho^{*}>\rho_{B}$, is also possible. In this equilibrium, the reputation abundant country "A" specializes in the reputation intensive sector $\alpha$ and country "B" specializes in the $\beta$ sector.

Proposition 4: Assume $(A 1-A 5)$. (a.) If $\rho_{\mathrm{A}}>\rho^{*}>\rho_{\mathrm{B}}$, then country A specializes in $\alpha$ sector goods and country $B$ specializes in $\beta$ sector goods. (b.) If, in addition, $\beta$ sector production in country $A$ is less costly by an amount $\zeta$, where $\zeta<\overline{\mathrm{P}}\left(\alpha, \mathrm{L}, \rho_{\mathrm{A}}\right)-\overline{\mathrm{P}}\left(\beta, \mathrm{L}, \rho_{\mathrm{B}}\right)$, then each country specializes in the sector in which they have a reputational comparative advantage and a technological comparative disadvantage.

The intuition behind proposition 4 is as follows. ${ }^{15}$ Consider two countries such as Switzerland and Ireland and suppose that the common conjecture about Swiss quality is higher than the common conjecture about Irish quality. Each country can produce linen, watches and a numeraire good such as potatoes. Suppose that low-quality watches and low-quality linen are equally valuable and equally costly to produce. Although high-quality linen is more valuable than low-quality linen, the value difference is not nearly as great as the price difference between high and low-quality watches. Now high-quality watch production is much more costly than high-quality linen production, therefore, a firm only produces high-quality watches if consumers believe with a sufficiently high probability that the unobservable quality is high. This consumer

\footnotetext{
${ }^{15}$ Proposition 4 only discusses specialization and not the pattern of trade. In particular, because of the assumed infinite elasticity of substitution between $\alpha$ and $\beta$ sector products, it is possible for each country to consume what they produce and export nothing. In addition there is a continuum of trading equilibrium. Although the pattern of trade is uniquely determined by reputational comparative advantage, the volume of exports and imports varies across the set of trading equilibria.
} 
belief is reputation dependant. Hence, Switzerland (with a sufficiently favorable reputation) produces watches and Ireland (with an unfavorable reputation) produces linen. Because a Swiss firm that produces linen is revealed as low quality, all low-quality Swiss firms produce watches and benefit from the Swiss reputation. Similarly for Irish firms and linen. If for some reason it is less costly, ex-ante, to produce linen in Switzerland and watch production costs are still invariant across countries, then Ireland has a technological comparative advantage in watch production. However, if Irish watches are (correctly) expected to be of very low quality, then the higher price received for Irish linen - the reputational comparative advantage - can determine the pattern of trade by overshadowing a small technological comparative disadvantage.

It is also possible that the reputation concerns each sector in each country. For example, Ireland may be conjectured as better in the linen sector and Switzerland as better in the watch sector. Or Switzerland may conjectured as better in both sectors, however, the Swiss reputation may be higher in the watch sector. It is easy to see that the reputational comparative advantage and the pattern of specialization in this case is the same as in Proposition 4. This is stated as a direct corollary of Proposition 3.

Corollary 1: Assume that $(A 1-A 4)$ are satisfied and that sector $\alpha$ and $\beta$ differ only in the country-oforigin quality conjectures. If $\rho_{\mathrm{A}}(\alpha) / \rho_{\mathrm{A}}(\beta)>1>\rho_{\mathrm{B}}(\alpha) / \rho_{\mathrm{B}}(\beta)$, then country A specializes in sector $\alpha$ goods and country $B$ specializes in sector $\beta$ goods.

In a world with many sectors, Corollary 1 suggests that a country might produce both $\alpha$ sector and $\beta$ sector goods. Proposition 4 makes the stronger claim that a country will specialize in only $\alpha$ or $\beta$ sector products. Furthermore, Proposition 4 suggests that observed sector reputations may, at a more primitive level, be driven by country-wide reputations.

\section{MNE}

In this section we analyze the relationship between country-of-origin reputation, sectors and the choice between internalizing production in a single firm, which we denote as FDI, and an arms length transaction between the host and parent which we denote as licensing. We provide a new rationale for 
MNE to arise and use this rationale to explain when FDI over licensing would occur. We then examine the effect of this reputation induced FDI on the host country's reputation.

It is often the case that a finished product requires both headquarter services and production services. Headquarter services may consist of design, engineering, marketing, management and, perhaps coordination of the multinational enterprise. As suggested above, these headquarter services are reputation intensive, or sector $\alpha$, activities. An immediate implication of Proposition 4 is that if headquarters services are reputation intensive activities and, if $\rho_{A}>\rho^{*}>\rho_{B}$, then country A is the parent and country B is the host in any MNE. ${ }^{16}$ Although specialization according to reputational comparative advantage may provide a novel explanation of some observed vertical MNEs, it does not provide an impetus for the MNE to internalize production in a single firm.

\section{A. Reputational Rents and the Choice Between licensing and FDI}

We consider an additional impetus for MNE. Our idea is that FDI allows the host firm to produce under the higher country-of-origin reputation of the parent firm and this generates production at a higher equilibrium by the host firm. We assume that this reputation transfer requires FDI rather than a less-costly licensing arrangement. ${ }^{17}$ That is, only when the parent firm is committed to the ongoing production process of the host firm (as in FDI) will consumer's beliefs change so that production can take place at the higher parent country equilibrium. Because licensing consists of a finite duration contract between the host and parent firm, consumers correctly separate the production facility reputation and the headquarters (or perhaps "brand") reputation.

We also take as given the sector of the good that each parent firm designs, and markets. That is, each parent firm produces headquarter services for a given sector $\alpha$ or sector $\beta$ product. Without this

\footnotetext{
${ }^{16}$ Although our framework differs, this rationale for vertical MNE has similarities with more traditional models of vertical MNE. In particular, the parent country is relatively abundant in the (reputation) factor which is used more intensively in headquarter services. This intra-MNE trade, therefore, mirrors the more general pattern of trade between the high-reputation parent and low-reputation host country.

${ }^{17}$ We do not attempt to model the structural change in the host firm that may facilitate this reputation transfer and instead we assume that FDI serves as a coordinating device. This topic represents an interesting area for further
} 
restriction all parent-country firms would choose the same sector. By restricting the sector choice of the parent firm we can analyze which sector is more likely to lead to FDI.

The additional cost of FDI over licensing for parent firm $\mathrm{j}$ is their FDI cost of $\lambda_{\mathrm{j}} \in[\underline{\lambda}, \bar{\lambda}]$, where $\lambda_{\mathrm{j}}$, is drawn from the smooth distribution function $\mathrm{F}_{\lambda}(\lambda)$. To simplify the analysis, we assume that although these FDI costs are firm specific, they are common knowledge and they are uncorrelated with the given firm-specific type or sector. There, therefore, exists an equilibrium whereby all firms in the parent country share the same reputation whether or not they become an FDI parent, $\rho_{A}($ FDI $)=\rho_{A}$, and we restrict attention to this equilibrium. These assumptions on the FDI costs and the method of reputation transfer are stated concisely as assumption 6.

$$
\begin{array}{ll}
F_{\lambda}(\underline{\lambda})=1-F_{\lambda}(\bar{\lambda})=0 ; F_{\theta}(\theta \mid \lambda)=F_{\theta}(\theta) ; F_{\lambda}(\lambda \mid \alpha)=F_{\lambda}(\lambda \mid \beta) ; \rho_{A}(F D I)=\rho_{A} . & \text { (A6a-FDI) } \\
\text { If } F(\theta \mid A)=F(\theta \mid B) \text {, then } \rho_{B}(F D I)=\rho_{A}(F D I) . & \text { (A6b-FDI) }
\end{array}
$$

The reputational rents created by FDI equal the difference in expected profits for a random host firm producing with reputation $\rho_{B}(\mathrm{FDI})$ to a random firm producing with reputation $\rho_{\mathrm{B}}(\sim \mathrm{FDI})$, where $\rho_{\mathrm{B}}(\sim \mathrm{FDI})$ is the conjecture about host firms that are not part of a FDI arrangement.

$$
\mathrm{R}\left(\rho_{\mathrm{B}}(\mathrm{FDI}), \rho_{\mathrm{B}}(\sim \mathrm{FDI}), \mathrm{S}^{\prime}, \mathrm{S}\right)=\mathrm{E}_{\theta} \mathrm{E} \Pi\left(\theta, \mathrm{S}^{\prime}, \mathrm{Q}, \rho_{\mathrm{B}}(\mathrm{FDI})\right)-\mathrm{E}_{\theta} \mathrm{E} \Pi\left(\theta, \mathrm{Q}, \mathrm{S}, \rho_{\mathrm{B}}(\sim \mathrm{FDI})\right)
$$

We start by considering a stylized model of FDI acquisition whereby neither the host nor the parent observe the host's type before purchase. This assumption ensures that all host firms are equally likely to be approached by a parent firm and that all host firms are equally likely to accept a parent firm's offer. It precludes the existence of an adverse selection or cream skimming problem in the acquisition of a hostcountry firm. Hence, an equilibrium with $\rho_{\mathrm{B}}(\sim \mathrm{FDI})=\rho_{\mathrm{B}}$, is possible and we initially restrict attention to this type of equilibrium. The modified timing of our model is as shown in Figure 3 below.

\section{FIGURE 3 GOES APPROXIMATELY HERE}

research, howe ver, its inclusion here would greatly lengthen the paper and would not change our main findings on how reputation affects the MNE's structure. 
We choose to abstract from issues that affect each parties bargaining power and the distribution of the reputational rents, however, given the model's structure a host firm would accept any price greater than $\mathrm{E}_{\theta} \mathrm{E} \Pi\left(\theta, \mathrm{Q}, \mathrm{S}, \rho_{\mathrm{B}}(\sim \mathrm{FDI})\right)$. This outcome is sufficient for the bargaining process itself to not preclude efficient outcomes from occurring, so that if $R\left(\rho_{A}, \rho_{B}(\sim F D I), S\right.$ ' $\left.S\right) \geq \lambda_{j}$ then firm " $j$ " in country "A" will be a FDI parent. The measure of FDI production in the host country is then given by:

$$
\operatorname{Pr}\left[\lambda_{j} \leq R\left(\rho_{A}, \rho_{B}, S^{\prime}, S\right)\right]=F_{\lambda}\left[R\left(\rho_{A}, \rho_{B}, S^{\prime}, S\right)\right]
$$

We now analyze the relationship between FDI and sectors and equilibrium reputations.

Proposition 5: If $A 1-A 6$ hold, $\mathrm{F}(\theta \mid \mathrm{A})=\mathrm{F}(\theta \mid \mathrm{B})$, and $\rho_{\mathrm{A}}>\rho^{*}>\rho_{\mathrm{B}}$, then: (a.) The measure of FDI is greater for sector $\alpha$ products; (b.) A higher reputation in the parent country increases their measure of outbound FDI; (c.) A lower reputation in the host country increases their measure of inbound FDI.

Proposition 5a shows that FDI is more likely for more sophisticated, or more reputation intensive, sector $\alpha$ products. This is a direct result of the single-crossing-property between sectors and conjectures that was demonstrated in the proof of Proposition 4. Expected profits increase faster in $\rho$ in sector $\alpha$ than in sector $\beta$, therefore, sector $\alpha$ generates greater reputational rents and more FDI.

For example, for more skill intensive products, where quality is not as easily verifiable at the time of purchase, a high reputation premium and, therefore, large reputational rents can be obtained by FDI. Hence, our model predicts the FDI rather than licensing that is found in the software, automobile and banking industries. On the other hand, many famous ready-to-wear brands such as Champion, Levi-Strauss and Nike produce the design and marketing of ready-to-wear clothing in the higher-reputation parent country, but garment construction is often performed by an affiliate in a lower-reputation country. There is less of an opportunity for reputational rents to be generated in garment construction and, therefore, our model predicts the licensing or joint ventures that are the usual division of production in the garment industry. The reputation premium, here, is more directly attributable to the brand name or the headquarter 
services. $^{18}$

The intuition behind Proposition 5b is that a higher reputation parent generates more reputational rents and, consequently, makes FDI more profitable. If all else is equal, then a higher reputation country has a greater percentage of FDI parent firms. The intuition behind Proposition $5 \mathrm{c}$ is similar. If all else is $\underline{\text { equal, }}$, then a lower reputation in the host country generates greater reputational rents and, therefore, FDI rather than licensing is more likely to occur in this low-reputation host country. A country that is perceived as potentially capable but remains stuck in a low-reputation equilibrium is a prime candidate for inbound FDI. Furthermore, by breaking a low-reputation equilibrium for the recipient host-country firms, FDI is potentially more beneficial than licensing to the host country. Hence, our results provide a rationale for an otherwise capable low-reputation host country to encourage FDI over licensing.

\section{B. Less Capable Host Country}

We now consider FDI when countries are not ex-ante equivalent. When countries are ex-ante identical the set of equilibria is the same and, therefore, the FDI induced high equilibrium production by a host firm can be described by the equivalent high parent country reputation. On the other hand, when countries differ in their production capabilities the set of possible equilibria differ as well. Although FDI can break a low-reputation equilibrium, the resulting production occurs at the most favorable equilibrium in the host country which is different from the parent country equilibrium.

Consider the following example. An uniform technological worsening in the host country increases $\mathrm{C}(\theta, \mathrm{Q})$ by the same constant amount $(\mathrm{k})$ for all firms. This increase generates a reduction in $\mathrm{F}\left(\theta\left(\rho_{\mathrm{i}}\right)\right)$ so that the equilibrium conjecture must decline in all stable equilibria. This uniform technological worsening is shown in Figure 4 as a downward shift of the graph in Figure 2. An uniform technological improvement has the opposite effect.

FIGURES 4 AND 5 GO APPROXIMATELY HERE

\footnotetext{
${ }^{18}$ For example, Morawetz (1981) describes a Colombian garment manufacturer that produced the same pair of pants, with and without the label of a prestigious foreign brand, for export to the Margarita Islands. The prestigious foreign label commanded a 21 percent price premium over the domestic label.
} 
Whereas a small technological difference across countries does not significantly alter our previous results a large difference has a very pronounced effect on the structure of MNE. In particular, if the increase in $C(\theta, Q)$ is sufficiently large, then, as shown in Figure 4, the highest possible equilibrium conjecture in the host country is less than $\rho^{*}$. In this case, the reputational rents are greater for $\beta$ sector goods. Although FDI helps to break the bad reputation equilibrium of the host country it cannot overcome its technological inferiority (perhaps emanating from a lack of skilled labor, necessary infrastructure or managerial capital) and the host country receives a greater measure of FDI in less sophisticated sector $\beta$ products. This discussion is summarized formally in Proposition 6.

Proposition 6: If A1-A6a are satisfied, and, if for the host country, $\max \left\{\rho_{\mathrm{B}} \mid \rho_{\mathrm{B}}=\mathrm{F}\left(\theta^{\mathrm{H}}\left(\rho_{\mathrm{B}}\right)\right)\right\}<\rho^{*}$, then the measure of FDI is greater for sector $\beta$ products.

Furthermore, the intuition behind (A4) suggests that multiple reputation equilibria are more likely to arise for sector $\alpha$ than for sector $\beta$ products. That is, by the given difference in sectors in (A5), the $\alpha$ sector is always more likely to satisfy (A4). If multiple equilibria occur only in sector $\alpha$, then reputational rents and FDI occur only in sector $\alpha$ as well and no FDI will occur for a host with sufficiently low production capability.

\section{Auxiliary Beliefs and Host Country Reputation}

The conjecture, $\rho_{\mathrm{b}}(\sim \mathrm{FDI})$, encompasses auxiliary beliefs that consumers have about the relationship between FDI and the expected quality of a home firm that is not part of a FDI relationship. In section IV.A. we considered an information structure such that FDI creates no auxiliary beliefs: $\rho_{b}(\sim F D I)=\rho_{b}$. In this section we analyze how different auxiliary beliefs could arise.

Spillover beliefs $\left(\rho_{b}(\sim F D I)>\rho_{b}\right)$, can arise for several reasons. First, if the host observes their type before deciding on the parent's offer (and if the parent's offer cannot be made contingent on the host's type), then only the highest type (lowest quality) host country firms would accept this offer and enter an FDI relationship. This adverse selection of lower quality host firms into an FDI relationship truncates the 
distribution of host country firms that are not part of a FDI relationship from above at some $\theta^{+}<\bar{\theta}$ so that $\mathrm{F}\left(\theta^{\mathrm{H}}\left(\rho_{\mathrm{i}}\right) \mid \theta<\theta^{+}\right)>\mathrm{F}\left(\theta^{\mathrm{H}}\left(\rho_{\mathrm{i}}\right) \mid \theta<\bar{\theta}\right)$ and as shown in Figure 5 the stable equilibrium conjecture for these remaining firms must increase. Second, technology and production knowledge from the parent firm may spillover to other firms in the host country. If these spillovers lower the cost of high quality by the same constant amount for all firms, then for any given conjecture, more firms choose high quality. As shown in Figure 4, this high-quality cost reduction generates an upward shift of the graph in Figure 2. Hence, when starting at any stable equilibrium, the equilibrium conjecture must increase. Spillover beliefs may also arise for purely expectation reasons. By Proposition 5 a large amount of FDI may be indicative of a capable host country that is stuck in a low-reputation equilibrium. Hence, after observing a large amount of FDI, consumer perceptions may change and generate a better equilibrium.

Condescending beliefs $\left(\rho_{b}(\sim \mathrm{MNE})<\rho_{\mathrm{b}}\right)$ arise if the FDI parent has superior information as to the type of a host country firm. In this case, the parent firm does not make a random draw from $F_{\theta}(\theta \mid B)$ but instead chooses firms that generate the greatest reputational rents and these are the highest quality (or lowest type) firms. This non-random draw truncates the distribution of remaining host firm types from below at some $\theta^{-}>\underline{\theta}$ so that $\mathrm{F}\left(\theta^{\mathrm{H}}\left(\rho_{\mathrm{i}}\right) \mid \theta>\theta^{-}\right)<\mathrm{F}\left(\theta^{\mathrm{H}}\left(\rho_{\mathrm{i}}\right) \mid \theta>\bar{\theta}\right)$ and as shown in Figure 5 the stable equilibrium conjecture for these remaining firms must decrease.

From equation (5) it is easy to see that reputational rents are higher for condescending beliefs than for spillover beliefs. Hence, there is more FDI for condescending than for spillover beliefs. One way of interpreting this result is that the objective of the parent firm and the host country may not be aligned. Perhaps a better interpretation is that when there are spillover beliefs the type of FDI we have identified here will diminish over time. Finally, note that the welfare effects of FDI are dependent on the form and magnitude of the auxiliary beliefs. If there are no auxiliary beliefs, or if spillover beliefs exist, or if condescending beliefs exist but are not too negative, then FDI is more beneficial than licensing to the host country.

\section{Conclusion}


For a firm without a readily identifiable brand name, quality reputation may solely reflect the country of origin. In this paper we endogenize country-of-origin reputations and show that otherwise identical countries can be correctly perceived as differing in their percentage of high-quality producers. These self-fulfilling reputations determine not only the average quality of a country's exports but also the type of products in which a country specializes. Hence, the pattern of international trade can be determined by reputational comparative advantage.

Reputational comparative advantage generates MNE for two reasons. First, many MNE products require the differing specializations of both the high and low reputation countries. Although differing in motivation, this result accords well with more traditional models of vertical MNE. We extend this analysis by showing how the presence of appropriable reputational rents can also generate MNE. This new impetus for MNE is of particular interest because it can distinguish between FDI (internalization within a single firm) and licensing (contracts between the parent firm and host country affiliate.) We find that FDI is more prevalent for more reputation intensive products unless the host has very low production capabilities, however, in this latter case the measure of FDI may be greatly reduced. Additionally, a higher reputation in the parent country generates more outbound FDI and (all things equal) a lower reputation in the host country generates more inbound FDI. FDI may have external effects on the host country's quality reputation. As long as the external effects are not too negative (they may very well be positive), the ability of FDI to generate production under a more favorable equilibrium makes it more beneficial than licensing to the host country. 


\section{References}

Armington, P. 1969. “A Theory of Demand for Products Distinguished by Place of Production," IMF Staff Papers, 16: 159-178.

Arrow, K. J. 1974. "The Theory of Discrimination," in O. Ashenfelter and A. Rees, eds., Discrimination in Labor Markets. Princeton, NJ: Princeton University Press.

Athey, S. 1998. "Comparative Statics Under Uncertainty: Single Crossing Properties and LogSupermodularity,” Massachusetts Institute of Technology Working Paper No. 96-22R.

Bagwell, K. and B. Staiger. 1989. "The Role of Export Subsidies When Product Quality Is Unknown," Journal of International Economics, 27: 69-89.

Bagwell, K. 1991. "Optimal Export Policy for a New-Product Monopoly,” American Economic Review, 81: 1156-1169.

Bilkey, W. and E. Nes. 1982. "Country-of-Origin Effects on Product Evaluations," Journal of International Business Studies, 13: 89-99.

Bodenhausen, G. and R. Wyer. 1985. "Effects of Stereotypes on Decision Making and InformationProcessing Strategies," Journal of Personality and Social Psychology, 48: 267-282.

Bodenhausen, G. and M. Lichtenstein. 1987. "Social Stereotypes and Information-Processing Strategies: The Impact of Task Complexity," Journal of Personality and Social Psychology, 52: 871-880.

Caves R. 1996. Multinational Enterprise and Economic Analysis. Cambridge, UK: Cambridge University Press.

Chiang, S. and R. Masson. 1988. "Domestic Industrial Structure and Export Quality," International Economic Review, 29: 261-270.

Chen, M. 1991. "The Role of R\&D Subsidies When Incomplete Information is an Entry Barrier," Journal of International Economics, 31: 251-270.

Ethier, W. 1986. “The Multinational Firm,” Quarterly Journal of Economics 101: 805-833.

Ethier, W., and J. Markusen. 1996. "Multinational Firms, Technology Diffusion and International Trade," Journal of International Economics 41: 1-28.

Grossman, G. and H. Horn. 1988. "Infant-Industry Protection Reconsidered: the Case of Informational Barriers to Entry," The Quarterly Journal of Economics, 103: 767-787.

Han, C. M. and V. Terpstra. 1988. "Country-of-Origin Effects for Uni-National and Bi-National Products," Journal of International Business Studies, 16: 235-255.

Hanson, G. 1994. "Localization Economies, Vertical Organization and Trade," American Economic Review 86: 1266-1278

Haucap, J., C. Wey and J. Barmbold. 1997 "Location Choice as a Signal for Product Quality: The Economics of "Made in Germany," Journal of Institutional and Theoretical Economics, 153: 510-531. 
Head, D. 1993. "Advertising Slogans and the 'Made-in' Concept," International Journal of Advertising, 7: 237-252.

Helpman, E. and P. Krugman. 1985. Market Structure and Foreign Trade. Cambridge, MA: MIT Press.

Holmstrom, B. and R. Myerson. 1983. "Efficient and Durable Decisions Rules with Incomplete Information," Econometrica, 51: 1799-1819.

Horstmann, I. and J. Markusen. 1987. "Licensing Versus Direct Investment: A Model of Internalization by the Multinational Enterprise," Canadian Journal of Economics 20: 464-81.

Horstmann, I. and J. Markusen. 1996. "Exploring New Markets: Direct Investment, Contractual Relationships and the Multinational Enterprise," International Economic Review 37: 1-20.

Markusen, J. 1989. "Trade in Producer Services and in Other Specialized Intermediate Inputs." American Economic Review 85: 85-95.

Markusen, J. 1995. "The Boundaries of Multinational Enterprises and the Theory of International Trade.” Journal of Economic Perspectives 9: 169-190.

Mayer, W. 1984. "The Infant-Export Industry Argument," Canadian Journal of Economics, 17: 249269.

Morawetz, D. 1981. Why the Emperor's New Clothes Are Not Made in Columbia. Oxford: Oxford University Press.

Rodríguez-Clare, A. 1996. Multinationals, Linkages, and Economic Development," American Economic Review 86: 852-874.

Tirole, J. 1996. "A Theory of Collective Reputations (with applications to the persistence of corruption and to firm quality)," Review of Economic Studies 63: 1-22.

Vernon, R. 1966. "International Investment and International Trade in the Product Cycle," Quarterly Journal of Economics, 80: 190-207.

Wortzel, L. and H. Wortzel. 1979. "Marketing Manufactured Exports from LDCs: Progress and Recommendations for Further Progress," Mimeo, Boston University, School of Management. 


\section{Appendix A: Proofs.}

(This appendix is made available for the referees, but is not part of the submitted paper.

It will be made available, upon request, for interested readers.)

Proof of Lemma 1: Suppose that $\mathrm{P}^{\prime}<\mathrm{u}(\mathrm{Z}, \mathrm{i})$ is the high bid. Then an importer that is not consuming all of the good can consume all of the good by choosing a price $\mathrm{P}^{\prime \prime}>\mathrm{P}^{\prime}$, where $\mathrm{P}^{\prime \prime}$ is arbitrarily close to $\mathrm{P}^{\prime}$. The increased consumption has a first-order effect on utility and the increased price has a second-order effect; therefore, some importer chooses the deviating price. Suppose instead that $\mathrm{P}^{\prime \prime \prime}>\mathrm{u}(\mathrm{Z}, \mathrm{i})$ is the high bid. Then an importer bidding $\mathrm{P}^{\prime \prime \prime}$ could choose a price equal to $\mathrm{u}(\mathrm{Z}, \mathrm{i})$. This deviating price eradicates a negative surplus and must increase utility; therefore, some importer would choose the deviating price.

Proof of Proposition 1: The proof of Proposition 1 requires a lemma that characterizes the comparative static properties of $\checkmark(\mathrm{Q}, \mathrm{i})$. We then combine the results of Lemma 2 with the properties of the cost function to show how $\rho_{\mathrm{i}}$ affects $\theta^{\mathrm{H}}$.

Lemma 2: (a.) $\checkmark(\mathrm{H}, \mathrm{i})>\checkmark(\mathrm{L}, \mathrm{i})$ and $\partial \checkmark(\mathrm{Q}, \cdot) / \partial \rho_{\mathrm{i}}>0$.

(b.) $\lim _{\rho \rightarrow 0}\left[\partial \checkmark(\mathrm{H} \cdot, \cdot) / \partial \rho_{\mathrm{i}}-\partial \checkmark(\mathrm{L} \cdot, \cdot) / \partial \rho_{\mathrm{i}}\right]>0 . \lim _{\rho \rightarrow 1}\left[\partial \checkmark(\mathrm{H} \cdot, \cdot) / \partial \rho_{\mathrm{i}}-\partial \checkmark(\mathrm{L} \cdot, \cdot) / \partial \rho_{\mathrm{i}}\right]<0$.

Proof of Lemma 2: (a.) First note that: $\frac{\partial b(\cdot, i)}{\partial Z}=\frac{-1 \frac{\partial L R(\cdot)}{\partial Z} \frac{1-\rho_{i}}{\rho_{i}}}{\left[1+\operatorname{LR}(Z) \frac{1-\rho_{i}}{\rho_{i}}\right]^{2}} \geq 0 ; \frac{\partial b(Z, \cdot)}{\partial \rho_{i}}=\frac{\frac{L R(Z)}{\left(\rho_{i}\right)^{2}}}{\left[1+L R(Z) \frac{1-\rho_{i}}{\rho_{i}}\right]^{2}}>0$.

By A3 we then have: $\partial \mathrm{u}(\mathrm{Z}, \cdot) / \partial \rho_{\mathrm{i}}=\partial \mathrm{b}(\mathrm{Z}, \cdot) / \partial \rho_{\mathrm{i}}[\mathrm{v}(\mathrm{H})-\mathrm{v}(\mathrm{L})]>0$; and

$\partial \mathrm{u}\left(\cdot, \rho_{\mathrm{i}}\right) / \partial \mathrm{Z}=\partial \mathrm{b}\left(\cdot, \rho_{\mathrm{i}}\right) / \partial \mathrm{Z}[\mathrm{v}(\mathrm{H})-\mathrm{v}(\mathrm{L})]>0$.

Part (a.) then follows from the above comparative statics, the FOSD of G(Z|Q) and Theorem 2 of Athey (1998, p.15).

(b.)

$$
\frac{\partial^{2} b(\cdot \cdot)}{\partial \rho_{i} \partial Z}=\frac{\frac{\partial \operatorname{LR}(Z)}{\partial Z} \frac{1}{\left(\rho_{i}\right)^{2}}\left[1-\operatorname{LR}(Z) \frac{1-\rho_{\mathrm{i}}}{\rho_{\mathrm{i}}}\right]}{\left[1+\operatorname{LR}(Z) \frac{1-\rho_{\mathrm{i}}}{\rho_{\mathrm{i}}}\right]^{3}}
$$


Taking limits yields: $\lim _{\rho \rightarrow 1} \frac{\partial^{2} \mathrm{~b}(\cdot, \cdot)}{\partial \rho_{\mathrm{i}} \partial \mathrm{Z}}<0 ; \quad \lim _{\rho \rightarrow 0} \frac{\partial^{2} \mathrm{~b}(\cdot,)}{\partial \rho_{\mathrm{i}} \partial \mathrm{Z}}>0$.

Now, $\partial^{2} \mathrm{u}(\cdot, \cdot) / \partial \mathrm{Z} \partial \rho_{\mathrm{i}}=\partial^{2} \mathrm{~b}(\cdot, \cdot) / \partial \mathrm{Z} \partial \rho_{\mathrm{i}}[\mathrm{v}(\mathrm{H})-\mathrm{v}(\mathrm{L})]$

Taking limits yields: $\lim _{\rho \rightarrow 0} \partial^{2} u(\cdot, \cdot) / \partial Z \partial \rho_{i} \geq 0$ and, $\lim _{\rho \rightarrow 1} \partial^{2} u(\cdot, \cdot) / \partial Z \partial \rho_{i}<0$.

The FOSD of G(Z|Q) and Theorem 2 of Athey (1998, p.15) implies that

$\operatorname{sign} \partial^{2} \mathrm{u}(\cdot, \cdot) / \partial \mathrm{Z} \partial \rho_{\mathrm{i}}=\operatorname{sign}\left[\partial \checkmark(\mathrm{H} \cdot, \cdot) / \partial \rho_{\mathrm{i}}-\partial \checkmark(\mathrm{L} \cdot, \cdot) / \partial \rho_{\mathrm{i}}\right]$.

Finally, the fact that $\partial^{2} \mathrm{C}(\theta, \cdot) / \partial \mathrm{Q} \partial \rho_{\mathrm{i}}=0$ indicates that $\operatorname{sign}\left[\partial \checkmark(\mathrm{H} \cdot, \cdot) / \partial \rho_{\mathrm{i}}-\partial \checkmark(\mathrm{L} \cdot, \cdot) / \partial \rho_{\mathrm{i}}\right]=$ $\operatorname{sign}\left[\partial \mathrm{E} \Pi(\theta, \mathrm{H} \cdot, \cdot) / \partial \rho_{\mathrm{i}}-\partial \mathrm{E} \Pi(\theta, \mathrm{L} \cdot, \cdot) / \partial \rho_{\mathrm{i}}\right]$.

Proof of Proposition 2: In Figure 2 we note that the intersection with the $45^{\circ}$ line indicates where $\rho_{\mathrm{i}}=$ $\mathrm{F}\left(\theta^{\mathrm{H}}\left(\rho_{\mathrm{i}}\right)\right)$. By (A4) and because the profit function is continuous in $\rho_{\mathrm{i}}, \mathrm{F}\left(\theta^{\mathrm{H}}\left(\rho_{\mathrm{i}}\right)\right)$ crosses the $45^{\circ}$ line from below at some $\rho_{\mathrm{i}}>0$, which ensures the existence of an equilibrium with some firms choosing high quality. Because the measure of firms choosing high quality is bounded below by zero, there must be another equilibrium with fewer firms choosing high quality. Because $\mathrm{F}\left(\theta^{\mathrm{H}}\left(\rho_{\mathrm{i}}\right)\right)>\rho_{\mathrm{i}}$ for some $\rho_{\mathrm{i}}$ there is a third equilibrium with more firms choosing high quality. To see this, note that $\mathrm{F}\left(\theta^{\mathrm{H}}\right)$ is bounded above by 1. Now either $\theta^{\mathrm{H}}(1)=\bar{\theta}$ so that $\rho_{\mathrm{i}}=1=\mathrm{F}\left(\theta^{\mathrm{H}}(1)\right)$ is an equilibrium, or $\theta^{\mathrm{H}}(1)<\bar{\theta}$ in which case $\mathrm{F}\left(\theta^{\mathrm{H}}\left(\rho_{\mathrm{i}}\right)\right)$ lies below the $45^{\circ}$ line at $\rho_{\mathrm{i}}=1$. Because $\mathrm{F}\left(\theta^{\mathrm{H}}\left(\rho_{\mathrm{i}}\right)\right)$ lies above the $45^{\circ}$ line at some $\rho_{\mathrm{i}}$, it must cross the $45^{\circ}$ line at a third equilibrium. If $\mathrm{F}\left(\theta^{\mathrm{H}}\left(\rho_{\mathrm{i}}\right)\right)$ crosses the $45^{\circ}$ line for a fourth equilibrium, the upper bound on $\mathrm{F}\left(\theta^{\mathrm{H}}\right)$ ensures that it would then cross it for a fifth equilibrium. Except for the non-generic case where $\mathrm{F}\left(\theta^{\mathrm{H}}\left(\rho_{\mathrm{i}}\right)\right)$ crosses the $45^{\circ}$ line at $\rho_{\mathrm{i}}=1, \mathrm{~F}\left(\theta^{\mathrm{H}}\left(\rho_{\mathrm{i}}\right)\right)$ must cross the $45^{\circ}$ line from above at the highest equilibrium $\rho_{\mathrm{i}}$. Hence, generically an odd number of equilibria exist. Because there are no restrictions on the curvature of $\mathrm{F}\left(\theta^{\mathrm{H}}\left(\rho_{\mathrm{i}}\right)\right)$, it may coincide with the $45^{\circ}$ line producing a continuum of equilibrium; however, this case exists with zero probability.

Proof of Proposition 3: First, note that the importer is indifferent (in the interim case) about the particular equilibria selected - their expected utility is $\mathrm{Y}$ in any equilibrium. Second, note that for any 
two equilibria where $\rho_{\mathrm{i}}^{\prime}>\rho_{\mathrm{i}}$ :

$$
\mathrm{E} \Pi\left(\theta^{\mathrm{H}}\left(\rho_{\mathrm{i}}\right), \mathrm{H}, \rho_{\mathrm{i}}{ }^{\prime}\right)>\mathrm{E} \Pi\left(\theta^{\mathrm{H}}\left(\rho_{\mathrm{i}}^{\prime}\right), \mathrm{H}, \rho_{\mathrm{i}}^{\prime}\right)=\mathrm{E} \Pi\left(\theta, \mathrm{L}, \rho_{\mathrm{i}}^{\prime}\right)>\mathrm{E} \Pi\left(\theta, \mathrm{L}, \rho_{\mathrm{i}}\right)=\mathrm{E} \Pi\left(\theta^{\mathrm{H}}\left(\rho_{\mathrm{i}}\right), \mathrm{H}, \rho_{\mathrm{i}}\right) .
$$

The first inequality is due to A1 and the definition of the marginal firm. The two equalities use the definition of $\theta^{\mathrm{H}}$. The second inequality is a result of Lemma 2a.

\section{Proof of Proposition 4:}

We first demonstrate a single crossing property between sectors and conjectures.

Lemma 3: $\partial \mathrm{E} \Pi(\theta, \alpha, \mathrm{Q}, \cdot) / \partial \rho_{\mathrm{i}}>\partial \mathrm{E} \Pi(\theta, \beta, \mathrm{Q}, \cdot) / \partial \rho_{\mathrm{i}}$.

Proof of Lemma 3: From A5 and Lemma 2a, we have:

$\partial \mathrm{u}(\alpha, \mathrm{Z}, \cdot) / \partial \rho_{\mathrm{i}}=\partial \mathrm{b}(\mathrm{Z}, \cdot) / \partial \rho_{\mathrm{i}}[\mathrm{v}(\alpha, \mathrm{H})-\mathrm{v}(\alpha, \mathrm{L})]>\partial \mathrm{b}(\mathrm{z}, \cdot) / \partial \rho_{\mathrm{i}}[\mathrm{v}(\beta, \mathrm{H})-\mathrm{v}(\beta, \mathrm{L})]=\partial \mathrm{u}(\beta, \mathrm{Z}, \cdot) / \partial \rho_{\mathrm{i}} \cdot$

By the FOSD of $G(Z \mid Q)$ and Theorem 2 of Athey (1998, p.15), we then have:

$\partial \overline{\mathrm{P}}(\alpha, \mathrm{Q}, \cdot) / \partial \rho_{\mathrm{i}}>\partial \overline{\mathrm{P}}(\beta, \mathrm{Q}, \cdot) / \partial \rho_{\mathrm{i}}$.

Because $\partial \mathrm{C}(\theta, \alpha, \mathrm{Q}) / \partial \rho_{\mathrm{i}}=\partial \mathrm{C}(\theta, \beta, \mathrm{Q}) / \partial \rho_{\mathrm{i}}=0$, the Lemma follows immediately.

(a.) By Lemma 3, the definition of $\rho^{*}$, and Proposition 3, if $\rho_{A}>\rho^{*}>\rho_{B}$, then

$\mathrm{E} \Pi\left(\theta, \alpha, \mathrm{H}, \rho_{\mathrm{A}}\right)>\mathrm{E} \Pi\left(\theta, \beta, \mathrm{H}, \rho_{\mathrm{A}}\right)>\mathrm{E} \Pi\left(\theta, \alpha, \mathrm{H}, \rho^{*}\right)=$

$$
\mathrm{E} \Pi\left(\theta, \beta, H, \rho^{*}\right)>\mathrm{E} \Pi\left(\theta, \beta, H, \rho_{B}\right)>\operatorname{E} \Pi\left(\theta, \alpha, H, \rho_{B}\right)
$$

Hence, high-quality country A firms choose sector $\alpha$ and high-quality country B firms choose sector $\beta$. A country A firm in sector $\beta$, therefore, generates posterior beliefs of $\operatorname{Pr}(\mathrm{H} \mid \beta, \mathrm{A})=0$. Now, by assumption, we have $\mathrm{C}(\theta, \alpha, \mathrm{L})=\mathrm{C}(\theta, \beta, \mathrm{L})$, therefore, it follows that:

$$
\mathrm{E} \Pi\left(\theta, \alpha, \mathrm{L}, \rho_{\mathrm{A}}\right)>\mathrm{E} \Pi(\theta, \alpha, \mathrm{L}, 0)=\mathrm{E} \Pi(\theta, \beta, \mathrm{L}, 0) .
$$

Therefore, all country A firms choose sector $\alpha$. Likewise, upon seeing a country B firm in sector $\alpha$, the posterior beliefs must be $\operatorname{Pr}(\mathrm{H} \mid \alpha, \mathrm{B})=0$. By the above argument, it is then true that

$$
\mathrm{E} \Pi\left(\theta, \beta, \mathrm{L}, \rho_{\mathrm{B}}\right)>\mathrm{E} \Pi(\theta, \beta, \mathrm{L}, 0)=\mathrm{E} \Pi(\theta, \alpha, \mathrm{L}, 0) .
$$

so that all country B firms choose sector $\beta$.

(b.) If country A production in the $\beta$ sector is cheaper by an amount $\zeta$, then country B has a 
technological comparative advantage in sector $\alpha$. Because the production cost is lower by $\zeta$ for either quality, the technological comparative advantage does not affect beliefs and, because it is sufficiently small, it cannot overcome the reputational comparative disadvantage.

Proof of Corollary 1: If $\rho_{A}(\alpha) / \rho_{A}(\beta)>1>\rho_{B}(\alpha) / \rho_{B}(\beta)$, then by Proposition 3 sector $\alpha$ products are more profitable in country " $\mathrm{A}$ " and sector $\beta$ are more profitable in country "B". Profit maximization by firms yields the hypothesized pattern of specialization.

Proof of Proposition 5: First note that without FDI all country B firms produce $\beta$ sector products.

(a.) By Proposition $\left.4 \mathrm{E} \Pi\left(\theta, S, Q, \rho_{A}\right)\right)-E \Pi\left(\theta, \beta, Q, \rho_{B}\right)$ is greater in sector $\alpha$. Furthermore, this result holds for all $\theta$, therefore, $\mathrm{E}_{\theta}\left[\mathrm{E} \Pi\left(\theta, \mathrm{S}, \mathrm{Q}, \rho_{\mathrm{A}}\right)-\mathrm{E} \Pi\left(\theta, \beta, \mathrm{Q}, \rho_{\mathrm{B}}\right)\right]$ is greater in sector $\alpha$. Because $\mathrm{E}_{\theta}[\cdot]$ is a linear operator this result holds for $\mathrm{E}_{\theta}\left[\mathrm{E} \Pi\left(\theta, \mathrm{S}, \mathrm{Q}, \rho_{\mathrm{A}}\right)\right]-\mathrm{E}_{\theta}\left[\mathrm{E} \Pi\left(\theta, \beta, \mathrm{Q}, \rho_{\mathrm{B}}\right)\right]$. By definition $\mathrm{F}_{\lambda}(\cdot)$ is an increasing function, therefore, $F_{\lambda}\left(R\left(\rho_{A}, \rho_{B}, \alpha, \beta\right)\right)=F_{\lambda}\left(E_{\theta}\left[E \Pi\left(\theta, \alpha, Q, \rho_{A}\right)\right]-\right.$ $\left.E_{\theta}\left[E \Pi\left(\theta, \beta, Q, \rho_{B}\right)\right]\right)>F_{\lambda}\left(E_{\theta}\left[E \Pi\left(\theta, \beta, Q, \rho_{A}\right)\right]-E_{\theta}\left[E \Pi\left(\theta, \beta, Q, \rho_{B}\right)\right]\right)=F_{\lambda}\left(R\left(\rho_{A}, \rho_{B}, \beta, \beta\right)\right.$.

(b.) and (c.) By Proposition $\left.3 \mathrm{E} \Pi\left(\theta, S, Q, \rho_{A}\right)\right)-E \Pi\left(\theta, \beta, Q, \rho_{B}\right)$ is strictly increasing in $\rho_{A}$ and strictly decreasing in $\rho_{B}$. Furthermore, this result holds for all $\theta$, therefore, $E_{\theta}\left[E \Pi\left(\theta, S, Q, \rho_{A}\right)-\right.$ $\left.\mathrm{E} \Pi\left(\theta, \beta, Q, \rho_{\mathrm{B}}\right)\right]$ is strictly increasing in $\rho_{\mathrm{A}}$ and strictly decreasing in $\rho_{\mathrm{B}}$. Because $\mathrm{E}_{\theta}[\cdot]$ is a linear operator this result holds for $\mathrm{E}_{\theta}\left[\mathrm{E} \Pi\left(\theta, \mathrm{S}, \mathrm{Q}, \rho_{\mathrm{A}}\right)\right]-\mathrm{E}_{\theta}\left[\mathrm{E} \Pi\left(\theta, \beta, \mathrm{Q}, \rho_{\mathrm{B}}\right)\right]$. By definition $\mathrm{F}_{\lambda}(\cdot)$ is an increasing function, therefore, $F_{\lambda}\left(R\left(\rho_{A}, \rho_{B}, S, \beta\right)\right)=F_{\lambda}\left(E_{\theta}\left[E \Pi\left(\theta, S, Q, \rho_{A}\right)\right]-E_{\theta}\left[E \Pi\left(\theta, \beta, Q, \rho_{B}\right)\right]\right)$ is strictly increasing in $\rho_{\mathrm{A}}$ and strictly decreasing in $\rho_{\mathrm{B}}$.

Proof of Proposition 6: Immediate from the proofs of Propositions 4 and 5. 


\section{Appendix B: Self-Fulfilling Reputations in a Noisy Price Signaling Model of Product Quality}

(This appendix is made available for the referees, but is not part of the submitted paper. It will be made available, upon request, for interested readers.)

The existence of multiple equilibrium that can be ranked by $\rho_{\mathrm{i}}$ does not depend on the inability of price to signal quality. To see this we consider the case of an explicit price signal of product quality. We show first that, if there is no noise in this signal, then a low-first period price can signal high quality to consumers. If this price signal is noisy, as a result of an unanticipated exchange rate fluctuation or an unanticipated shock to market demand, then multiple reputational equilibria are again possible. To simplify the analysis assume that the consumers receive no information about the product quality other than price and country of origin.

First, assume that $\mathrm{P}$ is perfectly observed. Let $\mathrm{C}(\theta, \mathrm{Q})$ be defined as before but assume that quality is chosen for both periods of a two-period game. Let units be chosen so that the value and cost of a low quality product are equal. Without loss of generality we can normalize this value to zero. Hence, under perfect information, $\mathrm{v}(\mathrm{L})=0=\mathrm{C}(\theta, \mathrm{L})$. A first period $\mathrm{P}_{1}<0$ will, therefore, eradicate low quality. All $\theta \leq \theta^{\mathrm{H}}$, where $\theta^{\mathrm{H}}$ is defined by $(1+\delta) \cdot \mathrm{C}\left(\theta^{\mathrm{H}}, \mathrm{H}\right)=\mathrm{P}_{1}+\delta \cdot \mathrm{v}(\mathrm{H})$, will choose high quality. If price is noisy because of, say, an unanticipated exchange rate shock, then the importer only observes $\mathrm{P}_{1}+\varepsilon$. If the above assumptions on the distribution of $\varepsilon$ are maintained, then the importers' posterior belief will be, in part, a function of their conjecture. A low conjecture reduces the posterior probability that a low price was chosen. Because a lower price signal is needed for the same probability of a high-quality sender, the benefit to choosing high quality is reduced in a country with an unfavorable reputation. As a result $\theta^{\mathrm{H}}$ drops and the reputation, and low conjecture, becomes self-fulfilling. 


\section{Appendix C: A Specific Factors Model}

(This appendix is made available for the referees, but is not part of the submitted paper.

$$
\text { It will be made available, upon request, for interested readers.) }
$$

The i identical agents in country i can sell their one endowed unit of labor to one of the $\mathrm{N}_{\mathrm{i}}$ manufacturing firms $\left(\mathrm{j} \in 1, \ldots, \mathrm{N}_{\mathrm{i}}\right)$ or to the numeraire sector in country $\mathrm{i}$. The $\mathrm{N}_{\mathrm{i}}$ manufacturing firms in country $\mathrm{i}$ are owned by the i agents who use their equal share of the firms' profits as well as their wage income to purchase goods. The numeraire good $\left(\mathrm{X}_{0}\right)$ is produced with a constant-returns-to-scale technology: $\mathrm{X}_{0 \mathrm{i}}={ }_{0 \mathrm{i}}$, where $\quad{ }_{0 \mathrm{i}}$ is the amount of labor used in numeraire production. The numeraire is freely tradable and can be used to rectify trade imbalances. Furthermore, because ${ }_{i}$ is assumed to be sufficiently large there is positive numeraire production in each country. The wage in each country is, therefore, equal to the price of the numeraire good which is normalized to one. The technology for producing the manufactured goods is as given in the previous section. In particular, with the wage equal to one, $\mathrm{C}\left(\theta_{\mathrm{j}}, \mathrm{Q}_{\mathrm{j}}\right)={ }_{\mathrm{mji}}$ represents the minimum cost function for each firm type. The labor demand by manufacturing firm $\mathrm{j}$ in country $\mathrm{i}$ is $\mathrm{mji}_{\mathrm{i}}$ so that the entire manufacturing labor demand in country $\mathrm{i}$ is mi. The resource constraint is, therefore, given as $\mathrm{X}_{0 \mathrm{i}}+\sum_{\mathrm{j}=1}^{\mathrm{N}_{\mathrm{i}}} \mathrm{C}\left(\theta_{\mathrm{j}}, \mathrm{Q}_{\mathrm{j}}\right)=\mathrm{oi}_{\mathrm{i}}+\mathrm{mi}_{\mathrm{i}} \leq \mathrm{i}$.

The manufactured goods are now produced for consumption by the agents in both countries.

These "consumers" take the place of the importers in the previous section. The agents' preferences can be represented by the utility function described in A3 and the agents' income is now endogenized as described above, therefore, their identical indirect utility functions can be represented as:

$\mathrm{V}(\mathrm{Z}, \mathrm{P}, \theta, \mathrm{i}, \quad)=\sum_{\mathrm{i}} \sum_{\mathrm{j}} \gamma_{\mathrm{ij}}\left(\mathrm{P}_{\mathrm{ij}}\right) \cdot\left[\mathrm{u}\left(\mathrm{Z}_{\mathrm{j}}, \mathrm{i}\right)-\mathrm{P}\left(\mathrm{Z}_{\mathrm{j}}, \mathrm{i}\right)\right]+\sum_{\mathrm{j}} \mathrm{E \Pi}\left(\theta_{\mathrm{j}}, \mathrm{i}\right) /_{\mathrm{i}}+1=\sum_{\mathrm{j}} \mathrm{E \Pi}\left(\theta_{\mathrm{j}}, \mathrm{i}\right) /{ }_{\mathrm{i}}+1$.

Equilibrium for country "i”" is then described by equations (E1 - E3) the above indirect utility function and the resource constraint. 


\section{Figure 1}

Timing of Actions and Information Structure

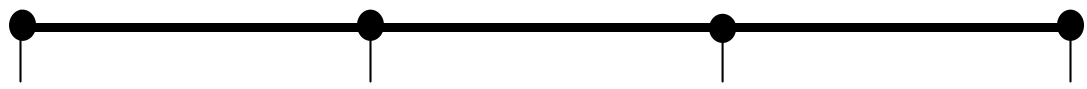

$\begin{array}{llll}\text { Firm receives } & \text { Firm observes } & \text { Importers observe } & \text { Firm sells to } \\ \{\theta, \mathrm{i}\} . & \begin{array}{l}\{\theta, \mathrm{i}\} \text { and } \\ \text { chooses } \mathrm{S} \text { and } \\ \text { then chooses } \mathrm{Q} .\end{array} & \begin{array}{l}\{\mathrm{i}, \mathrm{S}, \mathrm{Z}\} \text { and each } \\ \text { chooses } \mathrm{P} .\end{array} & \begin{array}{l}\text { highest } \mathrm{P} . \\ \text { Markets clear. }\end{array} \\ & & & \text { Payoffs received. }\end{array}$

\section{Figure 2}

$\underline{\text { Multiple Correct Equilibrium Beliefs }}$

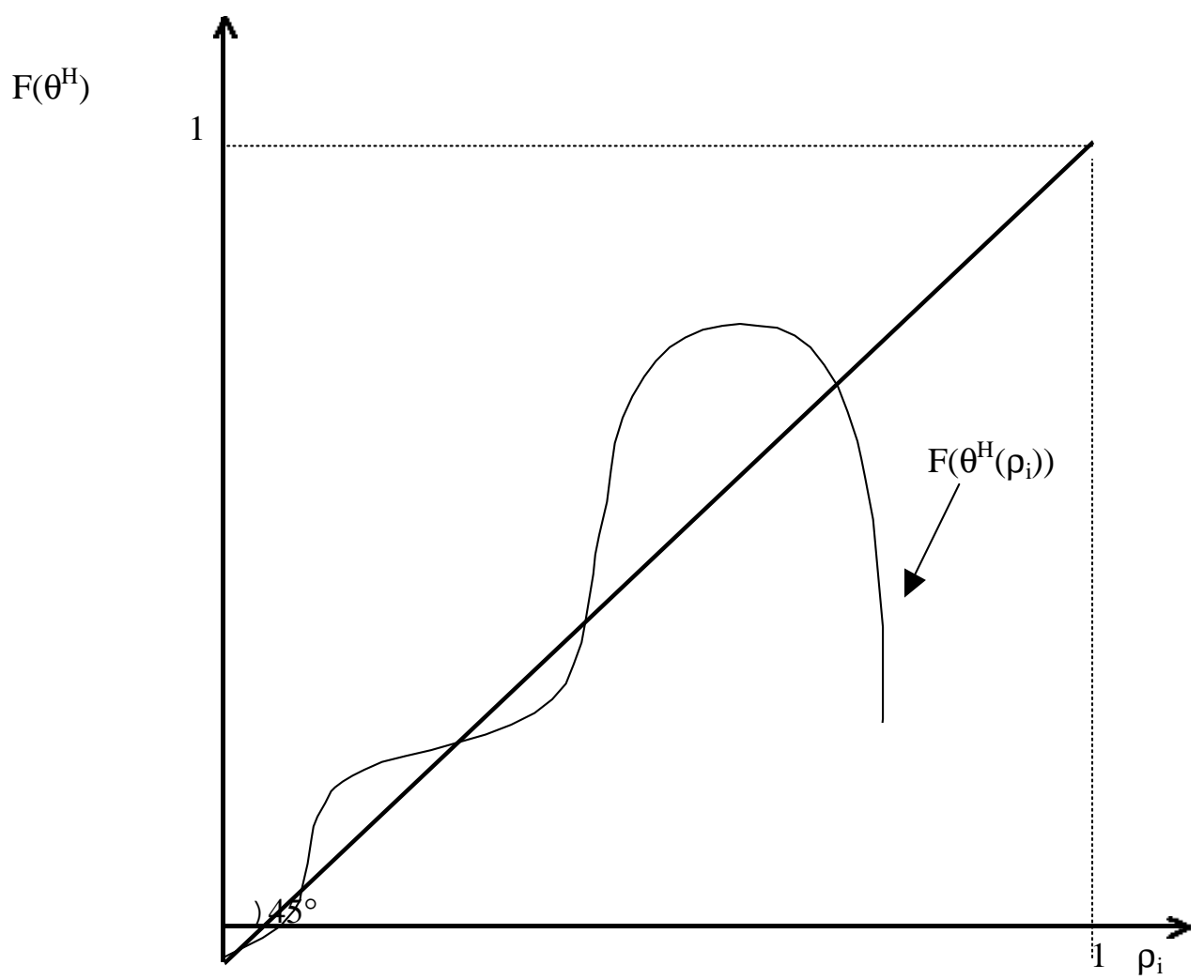




\section{Figure 3}

Timing of Actions and Information Structure With FDI and Licensing

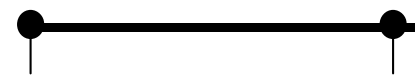

All firms receive $\{\theta, \mathrm{i}\}$. Country A firms receive

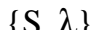

\section{Country A firms} observe $\{\theta, \mathrm{i}, \mathrm{S}, \lambda\}$. Each chooses whether or not to make an FDI offer to a randomly selected country B firm.

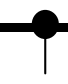

Each country B firm can accept or decline the FDI offer if it is made. They then observe $\{\theta, i\}$. They then choose $\mathrm{S}$ and then Q.
Consumers observe $\{\mathrm{S}, \mathrm{i}, \mathrm{Z}\}$ and the presence of FDI or licensing. They then choose P.

\section{Figure 4}

\section{Differing Production Capabilities and Technology Spillovers}

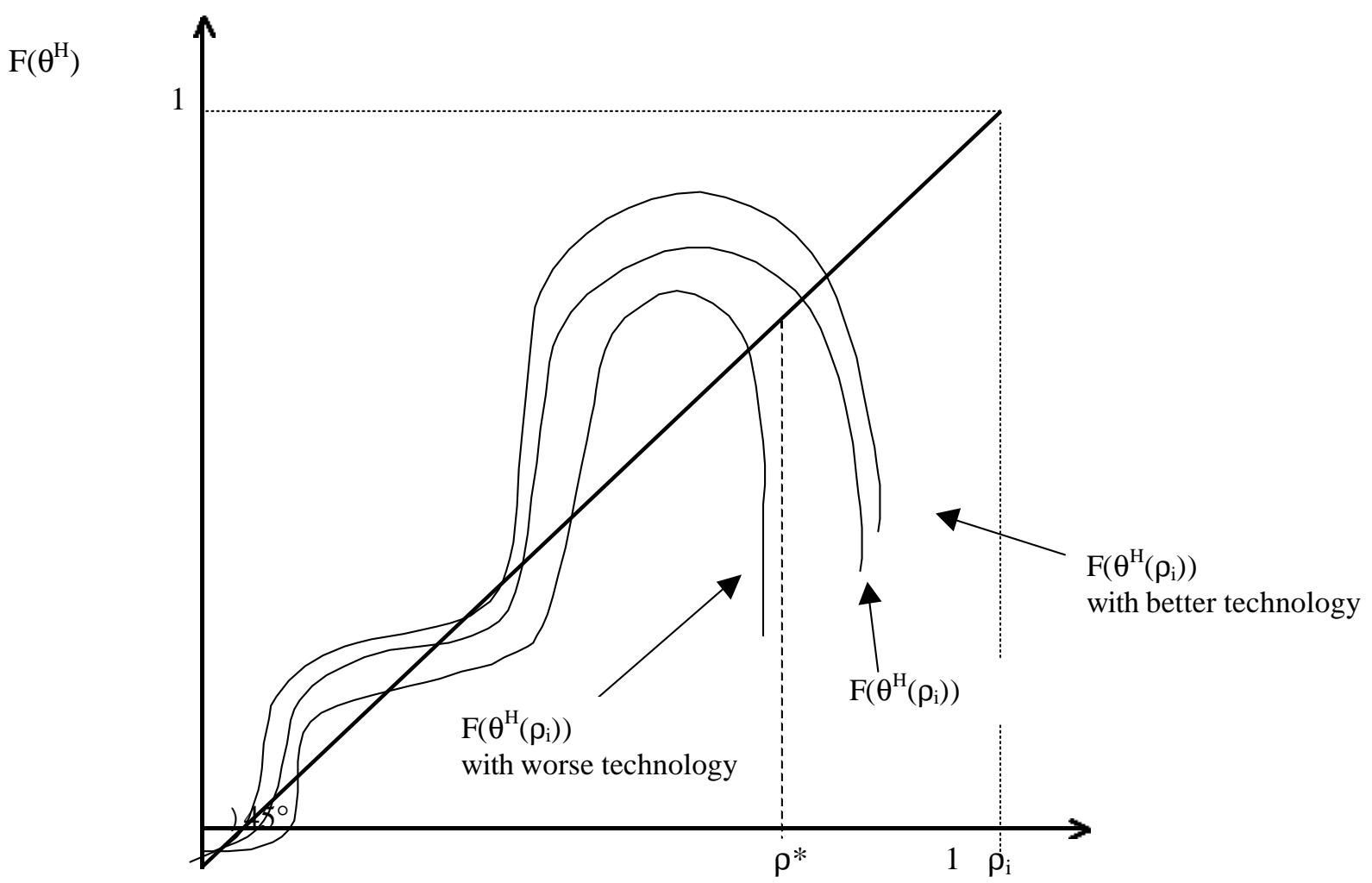

\section{Figure 5}


$\underline{\text { Spillover and Condescending Beliefs }}$

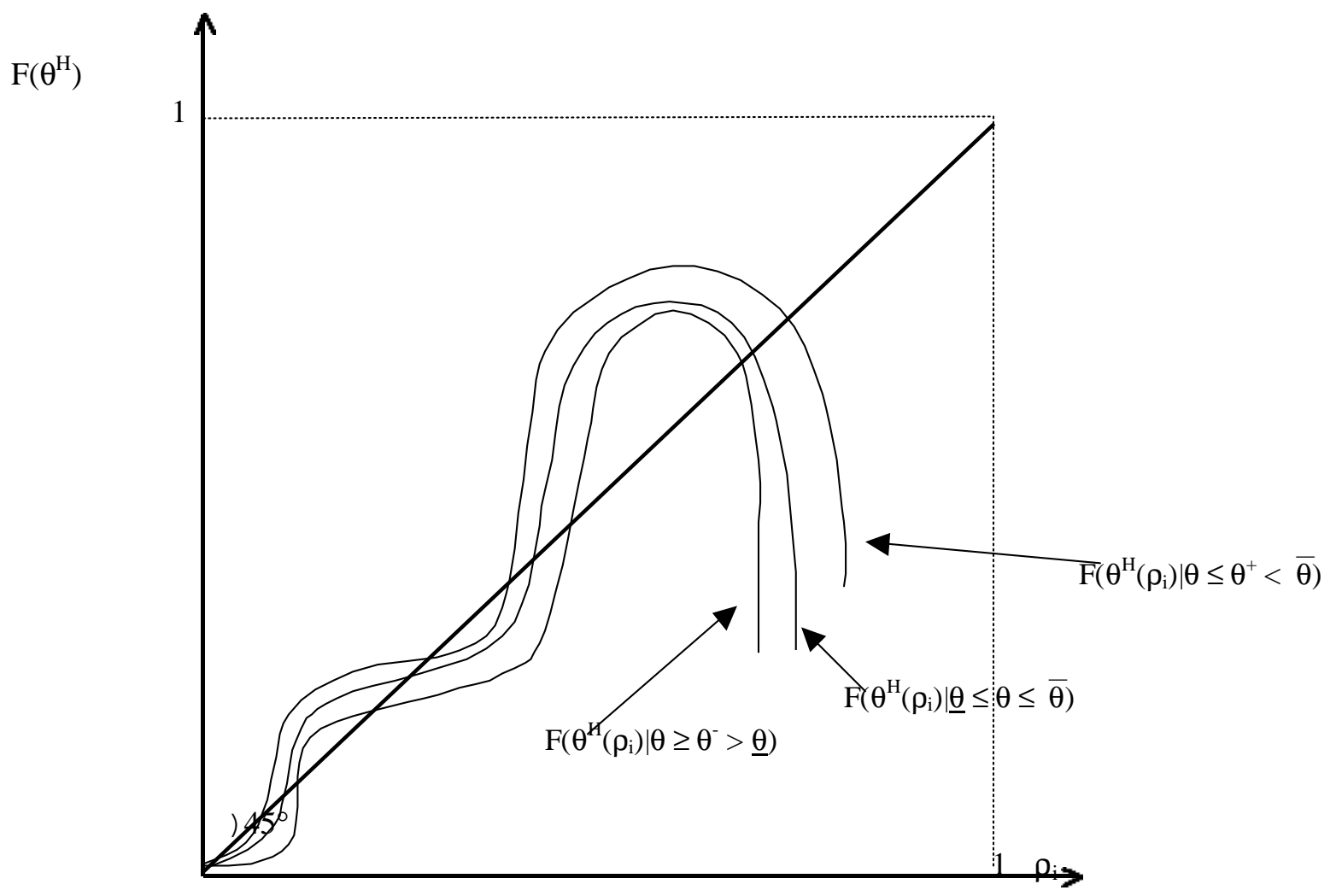

